\title{
Intranigral Fetal Dopamine Grafts Induce Behavioral Compensation in the Rat Parkinson Model
}

\author{
G. Nikkhah, ${ }^{1,2}$ C. Bentlage, ${ }^{1,2}$ M. G. Cunningham, ${ }^{3}$ and A. Björklund \\ 1Department of Medical Cell Research, University of Lund, S-223 62 Lund, Sweden, ${ }^{2}$ Neurosurgical Clinic, Nordstadt \\ Hospital, D-30167 Hannover, Germany, and 'Department of Brain and Cognitive Sciences, Massachusetts Institute of \\ Technology, Cambridge, Massachusetts 02139
}

Neural transplantation in experimental Parkinsonism has so far focused on the ectopic placement of fetal ventral mesencephalic (VM) neurons into the dopamine-denervated caudate-putamen. VM grafts are effective in restoring dopamine neurotransmission in the grafted caudate-putamen and in partial amelioration of behavioral deficits. Recent pharmacological and physiological data have provided strong evidence that dopamine released from dendrites of the substantia nigra pars compacta (SNc) neurons within the pars reticulata ( $\mathrm{SNr}$ ) plays an important role in the regulation of the basal ganglia output pathways. Using a novel microtransplantation approach, multiple small cell suspension grafts $(250 \mathrm{nl})$ derived from the VM of E14 rat embryos were implanted into the SNr of unilaterally 6-hydroxydopamine-lesioned rats. Behavioral changes in drug-induced rotation asymmetry were monitored for up to 14 weeks postgrafting, followed by a quantitative assessment and correlation of tyrosine hydroxylase (TH)-positive cell survival. The reduction in rotational asymmetry caused by the intranigral VM grafts was $64 \%$ for SKF 38393 (D1 agonist), $54 \%$ for apomorphine (mixed D1 and D2 agonist), and $67 \%$ for quinpirole (D2 agonist) when compared to a control spinal cord graft group. By contrast, amphetamine-induced rotation was completely unaffected. The correlation between number of THpositive cells and behavioral compensation was highest for the D1 agonist ( $R=-0.729$ ), though clear-cut also for the mixed D1/D2 agonist apomorphine $(R=-0.664)$ and the $D 2$ agonist quinpirole ( $R=-0.642$ ). Favorable morphological features of the VM micrografts included extensive migration of the dopaminergic neurons into the host $\mathrm{SNr}$ and the formation of dense patches of dendrite-like TH-positive terminal networks within the SNr. The results demonstrate a novel pattern of behavioral recovery induced by intranigral VM transplants in the rat Parkinson model. This may have important implications for the understanding of how the nigrostriatal dopamine system influences motor control in the

Received Aug. 27, 1993; revised Nov. 30, 1993; accepted Dec. 9, 1993.

We gratefully acknowledge the excellent technical support of Gertrude Stridsberg, Ulla Jarl, Maria Entezarjov, Agneta Persson, and Sten Nilsson, and thank Dr. Paul Greengard for the generous gift of the DARPP-32 antibody. We warmly thank Prof. Majid Samii and Prof. Robert Schönmayr for their continuous support. This study was supported by grants from Swedish MRC (04X-3874), the National Institute of Health (NS-06701), and the Göran Gustafson Foundation G.N. was supported by a grant from the Deutsche Forschungsgemeinschaft (DFG Ni 330/1-1).

Correspondence should be addressed to Guido Nikkhah, Neurosurgical Clinic, Nordstadt Hospital, Haltenhoffstrasse 41, D-30167 Hannover 1, Germany.

Copyright $(\mathcal{C} 1994$ Society for Neuroscience $0270-6474 / 94 / 143449-13 \$ 05.00 / 0$ basal ganglia as well as for the development of optimal transplantation strategies in Parkinson's disease.

IKey words: neural transplantation, dopamine, 6-hydroxydopamine, Parkinson, rotation, D1 agonist, D2 agonist, substantia nigra, dendritic release]

Intracerebral grafting has become an established tool to identify the functional implications of local restoration of transmitter release within a denervated or lesioned area in the brain. Dopamine released from ectopically placed intrastriatal grafts of fetal ventral mesencephalic (VM) tissue elicits a range of behavioral responses in the rat Parkinson model. It has been demonstrated that dopamine released from intrastriatal VM grafts can restore drug-induced locomotion and motor asymmetry, as well as some aspects of affected sensorimotor behavior, such as spontaneous turning and simple sensorimotor orientation deficits (for recent review see Björklund, 1992). Other behavioral deficits like food and water intake (Dunnett et al., 1983), hoarding behavior (Herman et al., 1986), and skilled paw use (Dunnett et al., 1987; Abrous et al., 1993) have been more resistant to graft-induced compensation.

There is increasing evidence that the nigrostriatal dopamine system exerts its function not only through transmitter release at the axonal terminals in the caudate-putamen, but also by release of dopamine from the dendrites within the substantia nigra (SN) itself. Dopaminergic mechanisms within the SN are likely to act in fine-tuning the outflow of basal ganglia information, mediated via dendritic release of dopamine in the substantia nigra pars reticulata (SNr) (Cheramy et al., 1981; for recent review, see Robertson, 1992). Dopamine D1 and D2 receptors occur in the $\mathrm{SNr}$ in a ratio of $15: 1$, compared to $2.5: 1$ in the caudate-putamen (Richfield et al., 1989). There is substantial evidence that the D1 receptor subtype is primarily located presynaptically on terminals of GABAergic striatonigral projections, whereas the D2 receptor subtype is likely to be located presynaptically on the dendrites of the dopaminergic nigrostriatal neurons of the substantia nigra pars compacta $(\mathrm{SNc})$, which project into the SNr (Cheramy et al., 1981; Robertson, 1992).

The functional significance of intranigral release of dopamine was suggested first by Kozlowski et al. (1980), who showed that local injections of the dopamine receptor agonist apomorphine into the $\mathrm{SNr}$ of 6-hydroxydopamine (6-OHDA)-lesioned rats results in vigorous contralateral rotations in a dose-dependent manner, and second by Jackson and Kelly (1983), showing that bilateral intranigral administration of haloperidol can reduce circling induced by systemic amphetamine in unilaterally 6-OHDA-lesioned rats. Cellular electrophysiological studies (for 
recent review, see Chevalier and Deniau, 1990) indicate that this effect may be mediated via GABA release from striatonigral axon terminals in the SNr. Further pharmacological experiments aimed at identifying which dopamine receptor subtype in the SN might be more important for the transduction of dopamine-induced effects led LaHoste and Marshall (1990) to propose that D1 receptors in the SN and D2 receptors in the striatum are primarily involved in the mediation of turning behavior induced by dopamine agonists.

L-Dopa, which is the current treatment of choice for Parkinsonian patients, also induces contralateral circling behavior in rats with unilateral 6-OHDA lesions (Robertson and Robertson, 1989). Interestingly, Robertson and Robertson (1989) found that the time course of $\mathrm{L}$-dopa-induced circling was more closely correlated with intranigral than intrastriatal dopamine concentrations. Similarly, Orosz and Bennett (1992) have reported that the L-dopa-induced increase in locomotor activity correlated with increases in nigral but not striatal extracellular levels of dopamine in 6-OHDA-lesioned rats.

In contrast to these pharmacological data, attempts to achieve functional effects with dopamine-rich grafts implanted into or near the SN have so far been unsuccessful (Dunnett et al., 1983; Robertson et al., 1991b). These authors attributed the lack of functional effects at least partly to poor graft survival and lack of integration seen with intranigral graft placement. Recently, the introduction of a modified microtransplantation approach has provided a new possibility to achieve better graft survival and integration (Nikkhah et al., 1994) and more extensive functional recovery by VM grafts implanted into the denervated striatum in the rat Parkinson's disease (PD) model (Nikkhah et al., 1993). This microtransplantation technique, which is based on the injection of submicroliter volumes of a single-cell suspension via a 50-70 $\mu \mathrm{m}$ glass capillary, allows for more precise graft placements into small brain structures and should thus be ideal for studies of morphological integration and functional effects of intranigral VM grafts.

The present study was designed to evaluate (1) the survival and morphological integration of VM micrografts implanted into multiple sites within the SN of 6-OHDA-lesioned rats, (2) the possible functional effects of intranigral VM micrografts as assessed with a range of drug-induced circling behaviors, (3) the importance of functional compartmentalization within the SN and hence graft localization within the $\mathrm{SN}$, and (4) the possible correlation between the extent of graft survival and behavioral recovery.

\section{Materials and Methods}

\section{Animals and 6-OHDA lesion surgery}

Female Sprague-Dawley rats (ALAB, Stockholm, Sweden), weighing $200-225 \mathrm{gm}$ at the time of surgery, were anesthetized by intraperitoneal injection of equithesin $(3 \mathrm{ml} / \mathrm{kg})$. Two stereotaxic injections of 6-hydroxydopamine (6-OHDA) $\mathrm{HB}_{\mathrm{r}}$ (Sigma) into the right ascending mesostriatal dopamine pathway were made using a $10 \mu$ l Hamilton syringe at the following coordinates (in millimeters, with reference to bregma and dura): (1) $2.5 \mu \mathrm{l}(3.6 \mu \mathrm{g} 6-\mathrm{OHDA} \mathrm{HBr} / \mu \mathrm{l}$ in $0.2 \mathrm{mg} / \mathrm{ml}$ $\mathrm{L}$-ascorbate-saline) at AP $-4.4, \mathrm{~L} 1.2, \mathrm{~V} 7.8$, tooth bar -2.4 ; (2) $3 \mu \mathrm{l}$ at AP $-4.0, \mathrm{~L} \mathrm{0.8,V} \mathrm{8.0,} \mathrm{tooth} \mathrm{bar}+3.4$. The injection rate was $1 \mu \mathrm{l}$ / $\mathrm{min}$ and the cannula was left in place for an additional $5 \mathrm{~min}$ before slowly being retracted.

\section{Analysis of rotational behavior}

Pregrafting. Two weeks after 6-OHDA lesion surgery, the animals were given $5 \mathrm{mg} / \mathrm{kg} d$-amphetamine (in saline) intraperitoneally and their rotational scores were collected over a $90 \mathrm{~min}$ period. The rotational behavior was monitored in automated "rotometer" bowls according to Ungerstedt and Arbuthnott (1970). Only rats exhibiting a mean net ipsilateral rotation of at least 6.4 full body turns $/ \mathrm{min}$, ipsilateral to the lesion, over the 90 min observation period were included in the study. The animals were further selected on the basis of their pregrafting contraversive rotational response, over a $40 \mathrm{~min}$ period, to the following dopamine receptor agonists: apomorphine $(0.05 \mathrm{mg} / \mathrm{kg}$, s.c.), at least 4.2 full body turns/min; D1 receptor-selective agonist SKF 38393 (2.5 $\mathrm{mg} / \mathrm{kg}$, i.p.), at least 3.5 full body turns $/ \mathrm{min}$. The D2 receptor-selective agonist quinpirole was also tested $(0.5 \mathrm{mg} / \mathrm{kg}$, i.p.) but not selected due to the overall lower rotational rate. The order of drug administration was always amphetamine, apomorphine, SKF 38393, and quinpirole in each test series. The time interval between the tests was 1 week, 3 $\mathrm{d}$, and $3 \mathrm{~d}$, respectively.

Postgrafting. The entire rotational test battery was repeated at 5 and 12 wccks postgrafting.

\section{Transplantation surgery}

The 6-OHDA-lesioned animals were divided into four equal groups with five animals in each (Table 1). The groups were balanced with respect to their rotational asymmetry scores.

Preparation and transplantation of dopamine-rich cell suspensions, obtained from ventral mesencephalic (VM) tissue of 14-d-old rat fetuses, were performed according to a modified microtransplantation approach (Nikkhah et al., 1994) based on the cell suspension technique described by Björklund et al. (1983) and Herman et al. (1986). To obtain a sufticient working volume for the cell suspensions, 31 ventral mesencephalons were dissected in DMEM (GIBCO) on each of two grafting sessions and the tissue was incubated in $0.1 \%$ trypsin (Worthington), $0.05 \%$ DNase (Sigma DN-25), DMEM at $37^{\circ} \mathrm{C}$ for $20 \mathrm{~min}$, and then rinsed four times in $0.05 \% \mathrm{DNase} / \mathrm{DMEM}$. The mechanical dissociation of the tissue pieces was performed in $250 \mu \mathrm{l}$ of $0.05 \%$ DNase/DMEM by repeated trituration starting with a $1 \mathrm{ml}$ Eppendorf pipette. After the suspension became milky a $200 \mu$ l Eppendorf pipette was used with its smaller tip for a second trituration in order to achieve a homogeneous single-cell suspension. The tissue was then centrifuged at $600 \mathrm{rpm}$ for $5 \mathrm{~min}$ and the pellet resuspended in a final volume of $95 \mu \mathrm{l}$ of $0.05 \%$ DNase/DMEM. The cell number of this cell suspension was $200,000-$ 210,000 cells $/ \mu$ l. The viability was $>98 \%$ at the beginning and $>86 \%$ at the end of the transplantation session, as determined by the trypan blue dye exclusion method.

The micrografts were implanted using a glass capillary with an outer diameter of 50-70 $\mu \mathrm{m}$ connected to a $1 \mu \mathrm{l}$ Hamilton microsyringe. Two deposits of $250 \mathrm{nl}$ were placed along each of the implantation tracks, resulting in a total of 8 (SN4A, SN4P) or 16 (SN8) micrografts with a total graft volume of 2 or $4 \mu$, equivalent to about $4-8 \times 10^{5}$ cells/ animal. The control group (SC) received grafts dissected from E14 spinal cord. The cell suspension was prepared as described above. The cell number was 151,000 cells $/ \mu$ l with a viability of $>96 \%$ pregrafting, and $>94 \%$ postgrafting.

The coordinates used for implantation are given in Table 1 . Over the course of the transplantation sessions the cells were gently triturated to maintain a homogeneous suspension, which is essential when using the thin glass capillaries for injection.

\footnotetext{
Figure 1. Camera lucida drawings of intranigral VM and spinal cord grafts at four representative levels through the anterior-posterior extension of the SN. Upper row, SN8 (eight VM graft deposits); middle row, SN4P (four VM graft deposits); lower row, SNC (three spinal cord graft deposits). Dots represent the distribution of TH-positive cells and the dashed lines outline the graft deposits. $C P$, cerebral peduncle; $I P$, interpeduncular nucleus; $M N$, mammillary nucleus; $O N$, oculomotor nerve; $S N c$, substantia nigra pars compacta; $S N r$, substantia nigra pars reticulata (depicted in gray on the lesioned and grafted side); $V T A$, ventral tegmental area.
} 


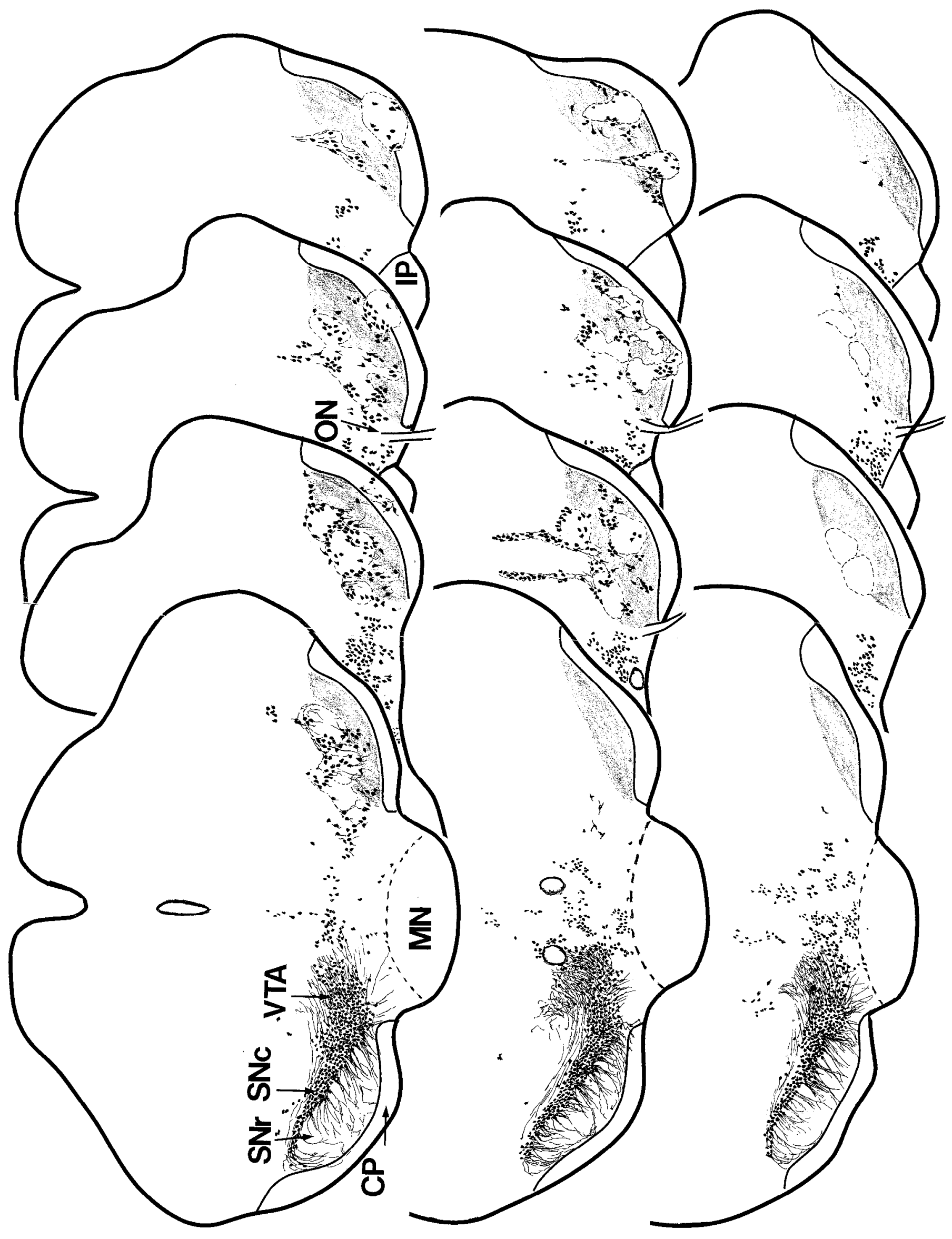




\begin{tabular}{|c|c|c|c|c|c|c|}
\hline \multirow[b]{2}{*}{ Group } & \multirow[b]{2}{*}{$n$} & \multicolumn{3}{|c|}{ Coordinates } & \multirow{2}{*}{$\begin{array}{l}\text { Total graft } \\
\text { volume }\end{array}$} & \multirow{2}{*}{$\begin{array}{l}\text { Total } \\
\text { cell no. }\end{array}$} \\
\hline & & $\mathrm{AP}$ & $\mathrm{L}$ & $\mathrm{V}$ & & \\
\hline \multirow[t]{3}{*}{ SN4A } & 5 & -5.9 & 1.6 & $7.4 \& 7.2$ & $2 \mu l$ & 400,000 \\
\hline & & & 2.2 & $7.0 \& 6.8$ & & \\
\hline & & -6.4 & \multicolumn{2}{|c|}{ as for AP -5.9} & & \\
\hline \multirow[t]{2}{*}{ SN4P } & 5 & -6.9 & \multicolumn{2}{|c|}{ as for $\mathrm{AP}-5.9$} & $2 \mu \mathrm{l}$ & 400,000 \\
\hline & & -7.4 & \multicolumn{2}{|c|}{ as for $\mathrm{AP}-5.9$} & & \\
\hline SN8 & 5 & \multicolumn{3}{|c|}{ SN4A \& SN4P together } & $4 \mu \mathrm{l}$ & 840,000 \\
\hline \multirow[t]{3}{*}{ SC } & 6 & -5.8 & 1.8 & $7.4 \& 7.2$ & $1.5 \mu \mathrm{l}$ & 230,000 \\
\hline & & & 2.4 & $6.7 \& 6.5$ & & \\
\hline & & -6.1 & 2.0 & $7.0 \& 6.8$ & & \\
\hline
\end{tabular}

$\mathrm{SN}$, substantia nigra; $\mathrm{A}$, anterior; $\mathrm{P}$, posterior; $\mathrm{SC}$, spinal cord.

\section{Immunohistochemistry}

One day after the last rotation test all animals were deeply anesthetized with chloral hydrate and perfused by the transcardiac route with $30 \mathrm{ml}$ of $0.9 \%$ saline, followed by $300 \mathrm{ml}$ of ice-cold $4 \%$ paraformaldehyde in $0.1 \mathrm{~m}$ phosphate buffer (PB, $\mathrm{pH} 7.4)$ over $9 \mathrm{~min}$. The brains were postfixed for $2 \mathrm{hr}$ and dehydrated overnight in $20 \%$ sucrose $/ 0.1 \mathrm{M}$ PB. Serial coronal sections were cut on a freezing microtome at $30 \mu \mathrm{m}$ thickness. Every third section was processed for tyrosine hydroxylase (TH) immunohistochemistry (1:500; Pel Freez; Nikkhah et al., 1994) using the $A B C-K i t$ and $D A B$ for visualization. Selected sections through the striatum and substantia nigra (SN) were double stained for TH (black precipitate using nickel-intensified DAB) and DARPP-32 immunoreactivity (brown precipitate using DAB only), following a modified $\mathrm{ABC}$ immunohistochemical protocol according to von Krosigk et al (1992; for details, see Groenewegen and Wouterlood, 1990) (DARPP32, 1:10,000; gift from Dr. P. Greengard; Wictorin et al., 1989).

TH-immunoreactive graft neurons were counted microscopically in every third section through the lesioned SN under bright-field illumination in the VM and control (SC) graft groups, and an approximation of the final graft cell number was calculated according to the formula of Abercrombie (1946). The counting was restricted to the SN proper (A9 cell group, Hökfelt et al., 1984), defined as the TH-positive cells located lateral to the medial terminal nucleus of the accessory optic tract, used to define the border between the ventral tegmental area (VTA) and the SN.

\section{Statistical analysis}

Results are expressed as means \pm SEM of the different treatment groups. For statistical evaluation, data were subjected to an unpaired two-tailed $t$ test (control vs grafted groups). Repeated measures were subjected to one-factor analysis of variance (ANOVA) and the Scheffer $F$ post hoc test. Correlation between the number of surviving TH-positive neurons and the degree of behavioral compensation in the groups with VM grafts was carried out via a simple regression analysis. For all statistical tests the significance level was set at $p<0.05$.

\section{Results}

\section{Survival of intranigral fetal VM grafts}

The dopaminergic micrografts, implanted as two $250 \mathrm{nl}$ deposits along four (SN4A and SN4P) or eight (SN8) needle tracks, tended to fuse to form spherical or oblong tissue strands along each needle track (Fig. 1). The grafts were mainly located in the dorsal part of the SN pars reticulata ( $\mathrm{SNr}$ ) and extended into, and sometimes through, the pars compacta (SNc) (Figs. 2, 3).

DARPP-32 was used as a marker for the SNr, because this D1 receptor-related protein is enriched in the terminals of the striatonigral projection, and it therefore heavily stains the $\mathrm{SNr}$. Numerous TH-positive cells of likely graft origin were found within the DARPP-32-positive SNr, and abundant TH-positive fibers extended from the graft deposits ventrally to form patches of TH-positive terminal networks within the surrounding $\mathrm{SNr}$ (Fig. $4 B, C$ ). The graft-derived TH-positive fibers, most of which had the morphological appearance of beaded dendrites, were almost exclusively confined to the SN (Fig. 3D). Some fibers were seen dorsally along the needle tracks but very few fibers occurred in the adjacent reticular formation or the white matter of the medial lemniscus (Fig. 3A). There was no obvious outgrowth of $\mathrm{TH}$-positive fibers rostrally along the nigrostriatal pathway. Very few TH-positive fibers can be seen in the denervated caudate-putamen on the SC control grafted side (Fig. 5); identical observations were made in the VM grafted animals (not shown).

In contrast to the rich TH-positive fiber outgrowth into the host $\mathrm{SNr}$, very little DARPP-32 staining was observed within the grafts, indicating that the host striatonigral projections did not send collaterals into the grafts (Figs. $3 B, 4 B$ ). However, many of the TH-positive neurons were located in the periphery of the graft deposits and some of them had apparently migrated in the host SNr. These cells, as well as their dendritic-like processes, were embedded in the DARPP-32-positive neuropil, suggesting possibilities for abundant direct contacts with the host striatonigral terminals (Figs. 3C, 4C). The control 6-OHDAlesioned animals, which had received spinal cord grafts into the $\mathrm{SN}$ (group SC), demonstrated few TH-positive neurons in the $\mathrm{SN}$ (mean $=71$; Fig. 6 ), and they were almost exclusively located in the medial part of the nucleus (Fig. 4A). These few THpositive nigral neurons, spared by the 6-OHDA lesion, correspond to only about $0.5 \%$ of the number of dopaminergic neurons normally present in the intact SN (see Discussion). The mean total number of surviving TH-positive neurons was 714 for group SN4A, 741 for group SN4P, and 1340 for group SN8 (Fig. 6).

\section{Amphetamine-induced rotation}

The net ipsilateral rotation response to amphetamine $(5 \mathrm{mg} / \mathrm{kg}$, i.p.) was recorded pregrafting, and 5 and 12 weeks after transplantation, as shown in Figure $7 \mathrm{~A}$.

The control SC group demonstrated a consistent, slightly increasing ipsilateral rotation rate, from 13 turns/min (pregrafting) to 16 turns/min (at 12 weeks postgrafting). This signifies $98 \%$ dopamine depletion of the 6-OHDA-lesioned striatum (Schmidt et al., 1983), and it is consistent with the very low TH-positive cell counts reported above. None of the grafted groups differed significantly from the $\mathrm{SC}$ group at any time point, nor did the 

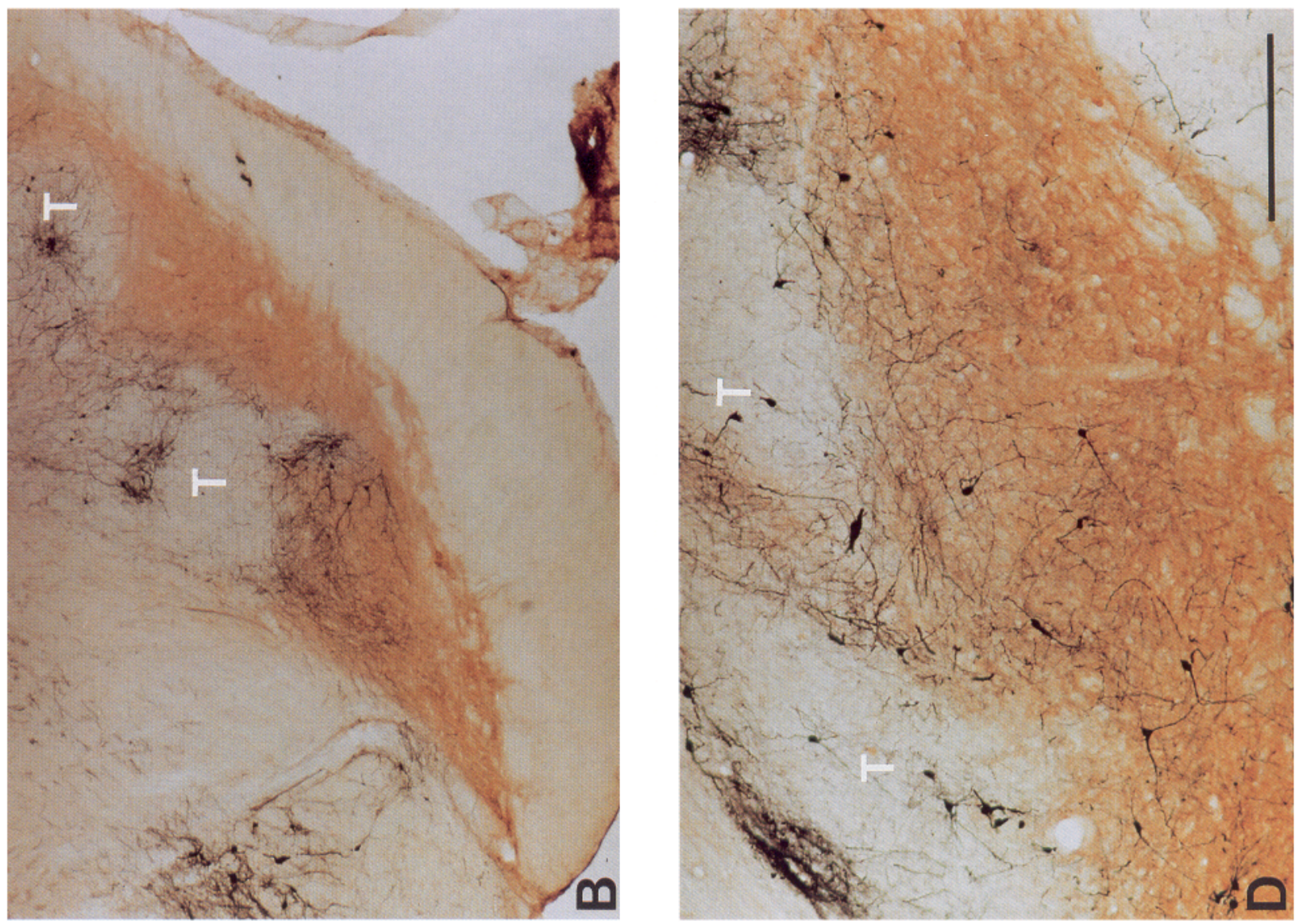

㟧

0

si

突

递.

奠

$\sum^{\infty}$

范

空空

댕

范

它

임

잉

응

ซิ

总占

产

自告

客皇

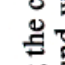
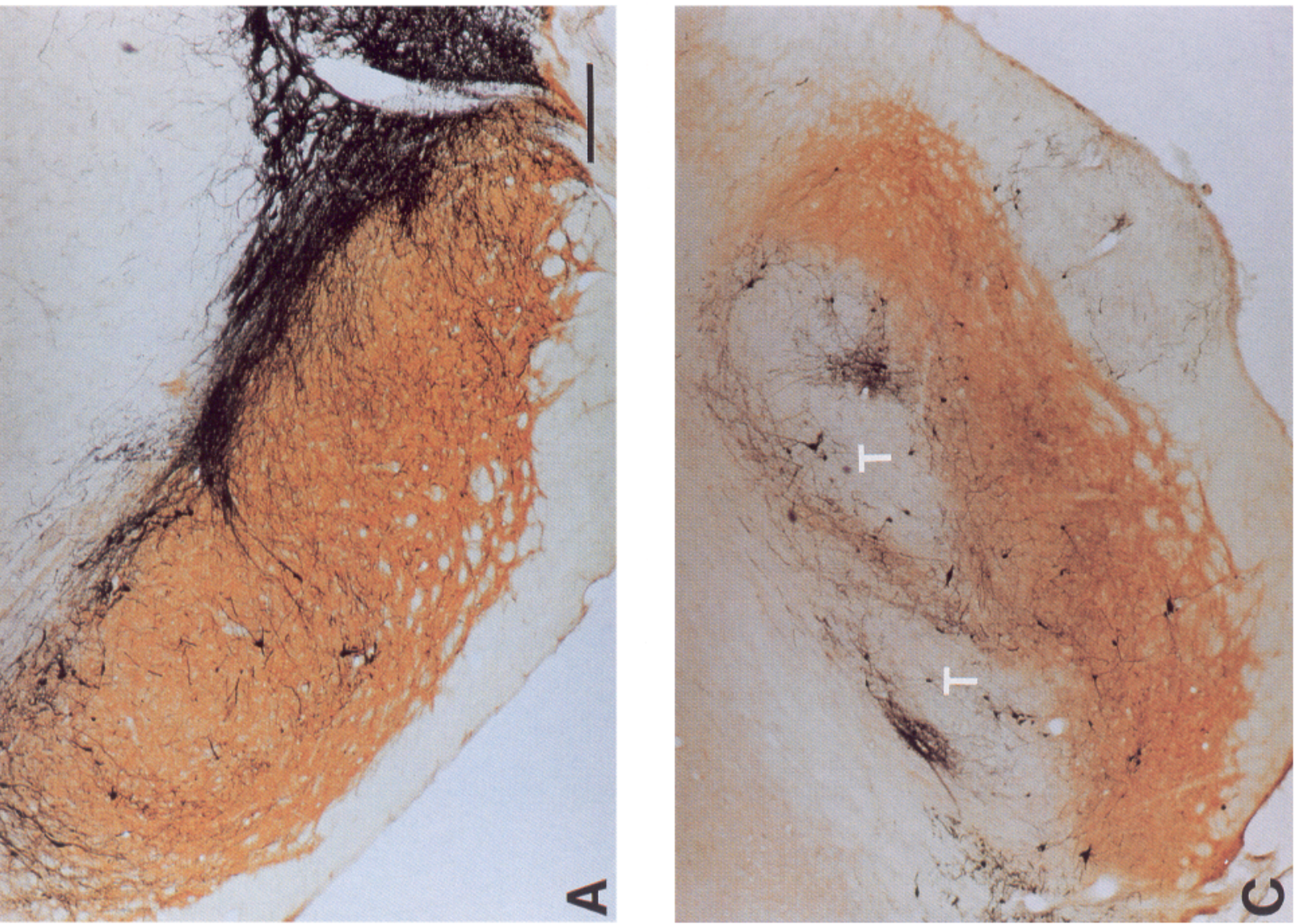

릉

표 8

흘

is

츤

I

.

둘

空

言

त

กิ?

웜

记

흥

z

के

政

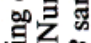

争

퐁 혼

:

貝응

ㅌ.

농

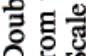

저

․ㅡ믐

今ํํำ

这击 돈 

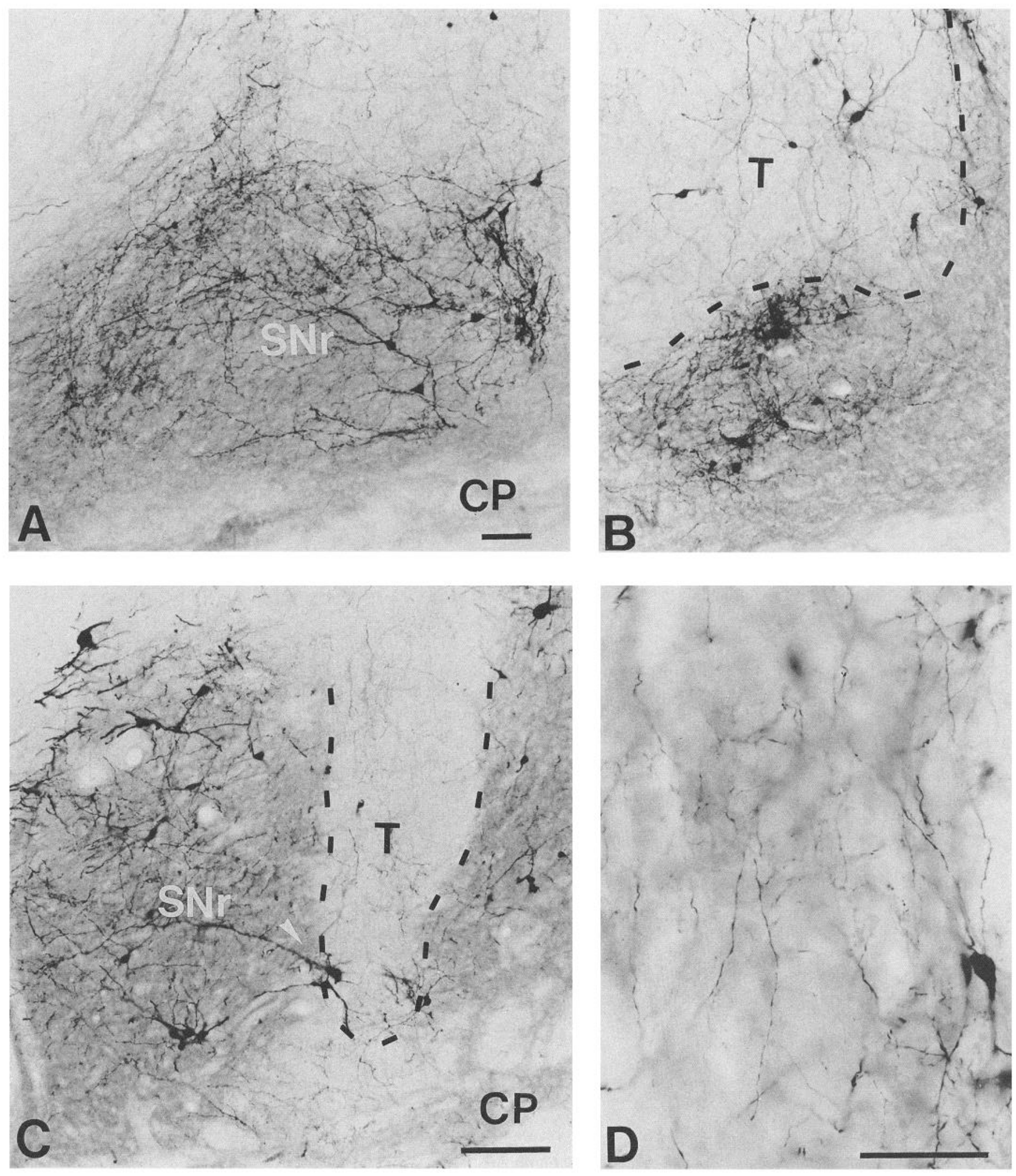

Figure 3. Photomicrographs illustrating TH-positive neurons (black) within the DARPP-32-positive (gray) host $\mathrm{SNr}\left(A-C^{\prime}\right)$ possessing dendriticlike processes $(D)$ and forming abundant patches of TH-positive terminal network. Scale bars, $100 \mu \mathrm{m}(B$ same as $A)$. 

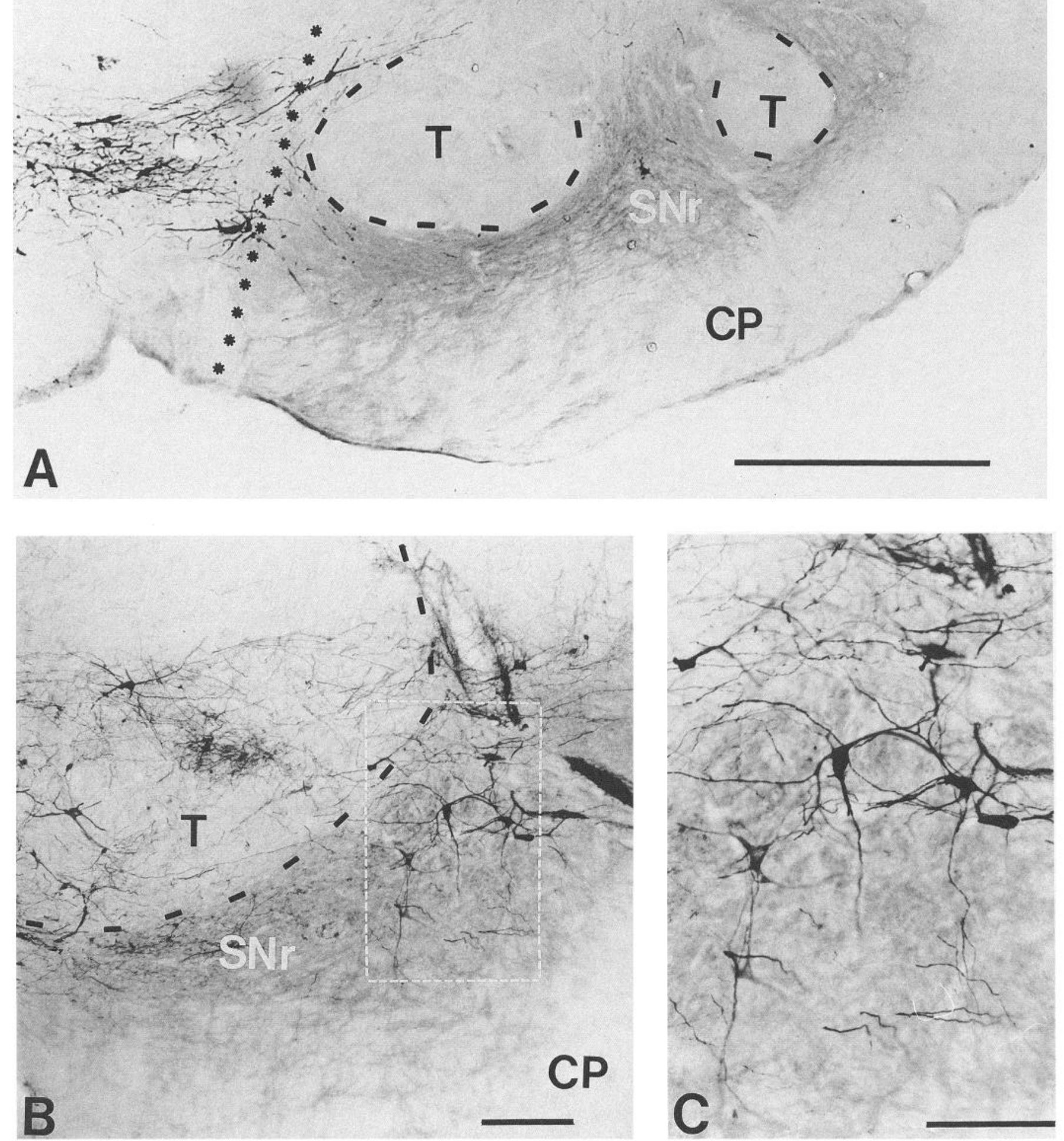

Figure 4. Photomicrographs illustrating the appearance of intranigral SC control grafts $(A)$ and VM grafts $(B, C)$. Note the absence of TH-positive neurons in the $\mathrm{SN}$ proper in the control grafts $(A)$. In contrast, numerous TH-positive neurons were found in the intranigral VM grafts $(B)$, where some seemed to have migrated into the adjacent $\mathrm{SNr}(C)$. Scale bars: $A, 25 \mu \mathrm{m} ; B$ and $C, 100 \mu \mathrm{m}$. 

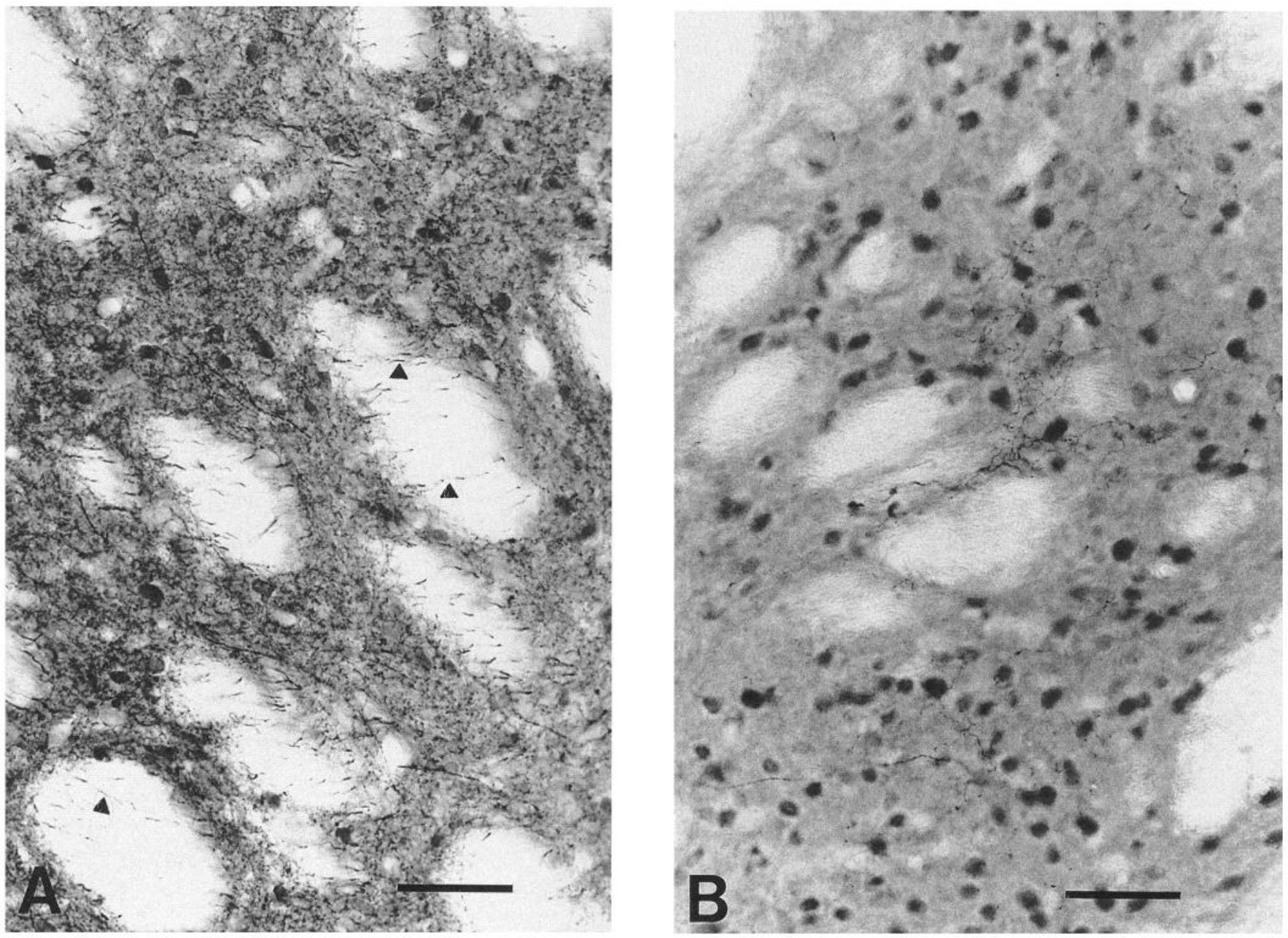

Figure 5. Double immunostaining of the caudate-putamen in a control SC animal for DARPP-32 (gray) and TH (black). There is an even and dense TH-positive fiber network surrounding the DARPP-32-positive striatal neurons $(A)$ on the control, unlesioned side, where some TH-positive fibers can also be seen coursing through the white matter of the internal capsule (arrowheads). In contrast, very few TH-positive fibers are visible on the lesioned and SC control grafted side $(B)$, which was the same in the VM grafted animals (not shown). Scale bars, $100 \mu \mathrm{m}$.

amphetamine-induced turning rates recorded after transplantation differ from their respective pregrafting scores.

\section{Apomorphine-induced rotation}

The combined D1 and D2 receptor agonist apomorphine $(0.05$ $\mathrm{mg} / \mathrm{kg}$, s.c.) induced eight mean contralateral full body turns/ min at 2 weeks after the 6-OHDA lesion (Fig. 7B). There was a significant reduction of the rotation asymmetry in the SN8 group, down to $54 \%$ of the SC group at 6 weeks $(p<0.008)$ and to $47 \%$ at 12 weeks $(p<0.002)$. This decrease in the rate of contralateral rotations in the $\mathrm{SN} 8$ animals was also significant when compared to their pregrafting values $(-41 \%, p=0.001)$. There was no such trend in the SN4A or SN4P groups, when evaluating the group means (NS from the SC group or pregrafting values), although some of the animals in these two groups did show clear-cut compensation (see below).

\section{SKF 38393-induced rotation}

Figure $7 C$ shows the rotational response induced by the D1selective agonist SKF 38393 ( $2 \mathrm{mg} / \mathrm{kg}$, i.p.). There was a strong contralateral rotation response in all four groups before transplantation (11-13 turns/min), which did not change at either 6 or 13 weeks after implantation in the SC, SN4A, and SN4P group. Only the SN8 group demonstrated a strong tendency toward a decreased response at 6 weeks $(-44 \%$ of the SC group, $\mathrm{NS})$, which became significant at 13 weeks postgrafting $(-64 \%$ of the SC group, $p<0.01)$. The reduction was significant also in comparison with the pregrafting scores of the SN8 group $(-60 \%, p<0.02)$.

\section{Quinpirole-induced rotation}

The overall lower rotational response to the $\mathrm{D} 2$-selective agonist quinpirole $(0.5 \mathrm{mg} / \mathrm{kg}$, i.p.) is illustrated in Figure $7 D$ (pregrafting: 3-5 full contralateral turns/min). Similar to the results obtained in the apomorphine-induced rotation test, animals from the SN8 group rotated significantly less than the SC group at 7 weeks $(-65 \%, p<0.05)$ and at 14 weeks $(-67 \%, p<0.05)$ after transplantation. This reduction, however, was not significantly different from the pregrafting values in the SN8 group because of the low mean values. The changes in the other groups were not significant at any time point.

\section{Correlation between rotational measures and surviving grafted dopamine neurons}

Since transplant-induced behavioral recovery was seen in most of the animals in the group with the more extensive grafts (i.e., 
No. of TH-positive neurons in the substantia nigra

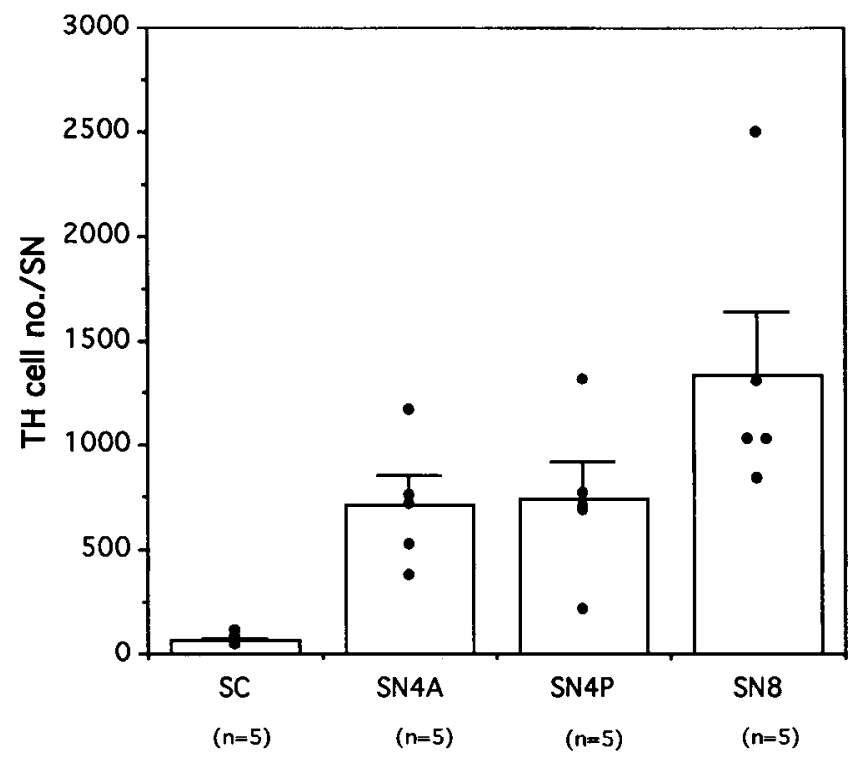

Figure 6. Number of TH-positive cells in the SN proper (see Materials and Methods) in the spinal cord control graft group $(S C)$ and in the VM graft group with anterior $(S N 4 A)$, posterior $(S N 4 P)$, and the combined anterior and posterior $(S N 8)$ intranigral graft placement. Dots show individual rats and bars represent group means + SEM.

SN8), but varied markedly among the animals in the two other VM graft groups, it was of interest to evaluate whether the extent of behavioral compensation was dependent on the number of surviving dopaminergic neurons in each animal. The data from the animals with fetal VM transplants were subjected to a simple regression analysis, as shown in Table 2 . The results of the postgrafting rotation tests (expressed as percentage of pregrafting rotation scores) were analyzed both nontransformed and $\log$ transformed to characterize further the nature of the correlation.

Generally, the comparison between the number of TH-positive neurons and the nontransformed rotational scores revealed a significant correlation, most strikingly for the D1 agonist SKF 38393 , but also for the D2 agonist quinpirole and the mixed agonist apomorphine, in both postgrafting tests. The correlation for the amphetamine test was much weaker and apparently caused by a single animal (see also Fig. $8 \mathrm{~A}$ ). Overall, the degree of correlation was higher when log-transformed rotational scores were used. This can be taken to suggest an exponential relationship between the number of surviving dopamine neurons in the grafted nigra and the reduction of the agonist-induced rotation, as illustrated in Figure 8.

From Figure 8 it can be seen that the degree of rotational asymmetry at 12-14 weeks after grafting (expressed as percentage of pregrafting values), induced by apomorphine (Fig. $8 B$ ), SKF 38393 (Fig. 8C), or quinpirole (Fig. 8D), declines with increasing numbers of surviving TH-positive neurons. This is less convincing, though significant, for amphetamine (Fig. 8A).

Inspection of the scatter plots suggests that the number of surviving dopaminergic transplant neurons necessary to induce any reduction in rotation asymmetry is similar for the three different dopamine agonists tested, and can be estimated at around 750 surviving TH-positive neurons (e.g., about $5 \%$ of the number of dopaminergic neurons of the intact SN; see Discussion below). To achieve a greater than $50 \%$ reduction of
Table 2. Simple regression analysis between the number of surviving transplant dopamine neurons and the rotation asymmetry expressed as percentage of pregrafting value (nontransformed and log transformed) in two postgrafting tests $(n=15)$

\begin{tabular}{|c|c|c|c|c|c|}
\hline \multirow[b]{2}{*}{ Drug } & \multirow{2}{*}{$\begin{array}{l}\text { Time } \\
\text { postgrafting }\end{array}$} & \multicolumn{2}{|c|}{ Nontransformed } & \multicolumn{2}{|c|}{ Log transformed } \\
\hline & & $R$ & $p$ & $R$ & $p$ \\
\hline \multirow[t]{2}{*}{ Amphetamine } & 5 weeks & 0.465 & 0.0811 & 0.608 & 0.0161 \\
\hline & 12 weeks & 0.546 & 0.0352 & 0.580 & 0.0233 \\
\hline \multirow[t]{2}{*}{ Apomorphine } & 6 weeks & 0.631 & 0.0116 & 0.803 & 0.0003 \\
\hline & 13 weeks & 0.664 & 0.0069 & 0.776 & 0.0007 \\
\hline \multirow[t]{2}{*}{ D1 (SKF38393) } & 6 weeks & 0.724 & 0.0023 & 0.859 & 0.0001 \\
\hline & 13 weeks & 0.729 & 0.0020 & 0.831 & 0.0001 \\
\hline \multirow[t]{2}{*}{ D2 (quinpirole) } & 7 weeks & 0.640 & 0.0102 & 0.558 & 0.0306 \\
\hline & 14 weeks & 0.642 & 0.0099 & 0.731 & 0.0019 \\
\hline
\end{tabular}

rotational asymmetry, about 1000-1300 TH-positive neurons seem to be required. In all VM grafted groups the behavioral effect seemed to be correlated with the total number of surviving TH-positive neurons, regardless of the number of graft deposits, or graft placement within the nigra (anterior vs posterior part).

\section{Discussion}

The present results demonstrate, for the first time, the ability of intranigral VM grafts to cause a marked alleviation of dopamine receptor agonist-induced rotational asymmetry in the rat $\mathrm{PD}$ model. The fetal VM transplants were dispersed as two small deposits (250 $\mathrm{nl}$ each) over four or eight injection tracks in the SNr. The total size of the grafts used here was about 4$8 \times 10^{5}$ cells per rat, equivalent to the amount obtained from one to two fetal mesencephali. The functional effects of intranigral dopaminergic micrografts were most pronounced for the D1 receptor-selective agonist SKF 38393 and less prominent though clear-cut for the D2-selective agonist quinpirole and the mixed D1 and D2 agonist apomorphine.

With multiple microtransplants, as used here, it was possible to achieve a considerably greater degree of graft integration than previously reported. In two studies (Björklund et al., 1983; Robertson et al., 1991) where intranigral VM grafts were performed, dopamine neurons did not show any tendency for migration into the host and they did not extend TH-positive fibers into the adjacent $\mathrm{SNr}$. In the present study dopamine neurons from VM micrografts were found to migrate into the DARPP-32positive $\mathrm{SNr}$ and to form dense patches of TH-positive terminal networks within the SNr. This would allow the formation of functional synaptic contacts with the D1 receptor-bearing striatonigral terminals as well as a dopamine release in their direct vicinity.

The previous attempts to implant dopaminergic neurons into the 6-OHDA-lesioned SN have met with difficulties (Dunnett et al., 1983; Doucet et al., 1989; Robertson et al., 1991b) because of the smaller size of the target structure. Here, the microtransplantation procedure, as modified from our intrastriatal VM micrografts (Nikkhah et al., 1994), allows more precise and reproducible implantations with less tissue damage than the "standard" transplantation approach. Another significant drawback is the markedly lower survival rate of homotopically implanted fetal dopaminergic neurons. Present data shows a sevento eightfold lower survival rate in the SN compared to similar VM transplants placed into the striatum (Nikkhah et al., 1994). 

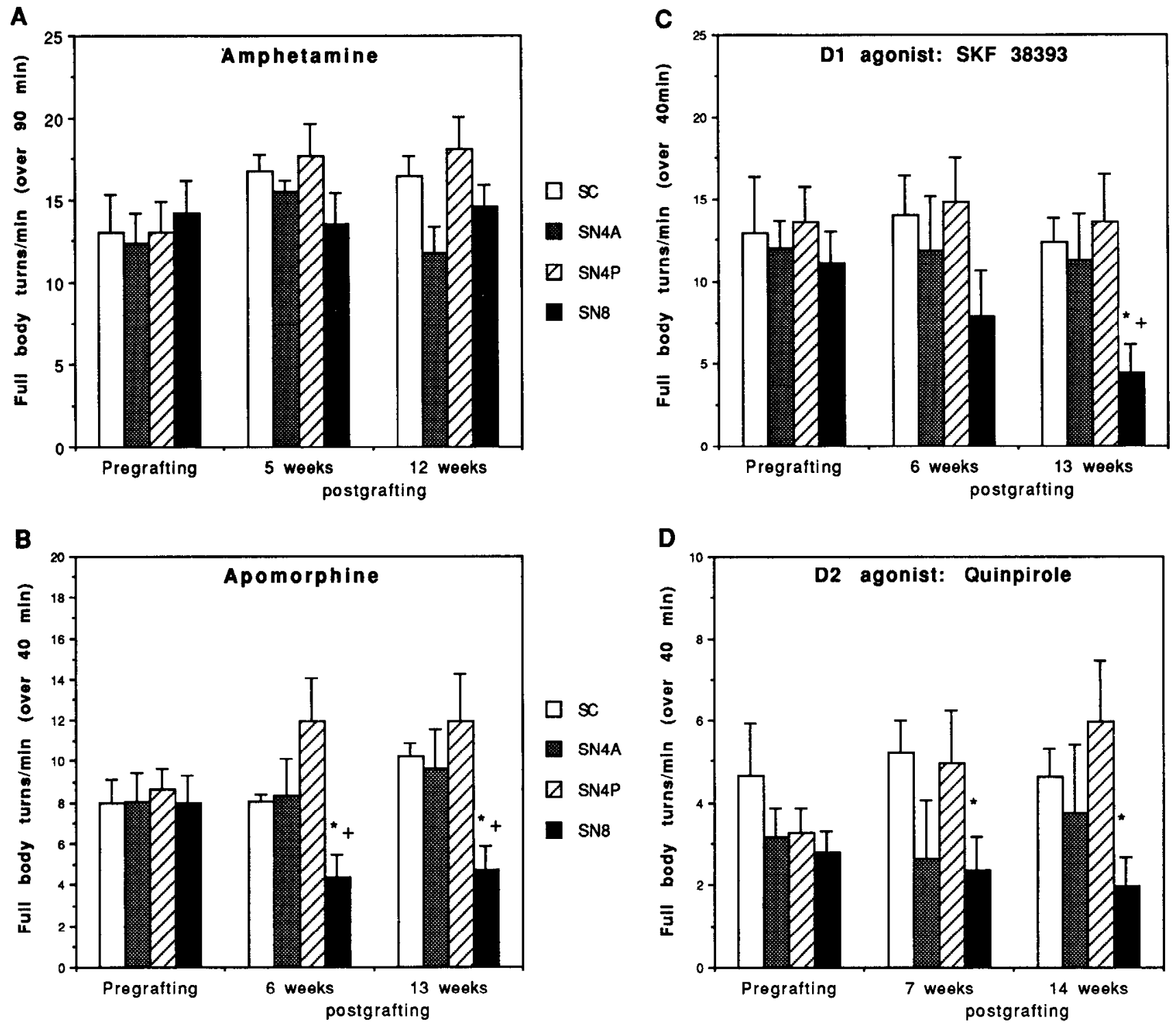

Figure 7. Pre- and postgrafting rotation scores for amphetamine $(A ; 5 \mathrm{mg} / \mathrm{kg}$, i.p.), apomorphine $(B ; 0.05 \mathrm{mg} / \mathrm{kg}, \mathrm{s.c}$.), SKF $38393(C ; 2 \mathrm{mg} / \mathrm{kg}$, i.p.), and quinpirole $(D ; 0.5 \mathrm{mg} / \mathrm{kg}$, i.p.) expressed as mean ( $+\mathrm{SEM})$ full body turns $/ \mathrm{min}$, ipsilateral over 90 min for amphetamine, and contralateral over 40 min for the three DA agonists. *, significant difference from SC control group, unpaired $t$ test, $p<0.008$ for apomorphine and SKF 38393 , $p<0.04$ for quinpirole; + , significant difference from pregrafting scores, ANOVA with post hoc Scheffe $F$ test, $p<0.002$ for apomorphine, $p<$ 0.02 for SKF 38393.

In the intrastriatal VM micrografts the yield of surviving dopamine neurons was on the average $12 \mathrm{TH}$-positive neurons per 1000 cells implanted (Nikkhah et al., 1994), whereas the yield in the present intranigral VM micrografts was $1.6-1.8 \mathrm{TH}$ positive neurons per 1000 cells. Consequently, the minimum number of implanted cells necessary to obtain any functional effects would be seven- to eightfold higher in the SN than in the caudate-putamen. In fact, since it appears that twice as many surviving $\mathrm{TH}$-positive neurons are required to induce a significant reduction of drug-induced turning in the $\mathrm{SN}$ compared to grafts in the striatum (see below), it seems that one needs in the order of 10-15 times more implanted cells for significant functional effects in SN. This can be achieved only by spreading the graft tissue over multiple injection sites and simultaneously keeping the surgical trauma to a minimum. This readily explains why no functional effects have been obtained in earlier studies.

The implantation of fetal VM neurons into the denervated striatum can restore dopaminergic neurotransmission and normalize dopamine receptor supersensitivity within the transplanted caudate-putamen (for a recent review, see Björklund, 1992). More distant transplant-induced effects have also been observed. For example, the increase of D1 receptor binding in the SN ipsilateral to the 6-OHDA lesion was normalized 1012 months after intrastriatal VM grafts (Dawson et al., 1991). This indicates that dopamine receptor changes in the striatonigral projection neurons can be expressed at the axon terminal level (i.e., in the $\mathrm{SN}$ ) when the dopaminergic innervation is confined to the cell body level (i.e., in the caudate-putamen). The present results demonstrate that a similar downregulation of the D1 receptor can be induced by a dopamine input to the $\mathrm{SN}$ itself.

Therefore, it seems reasonable to assume that intranigral VM grafts arc able to reinstatc functional dendritic dopamine rcleasc, sufficient to reverse the lesion-induced receptor supersensitivity 
A
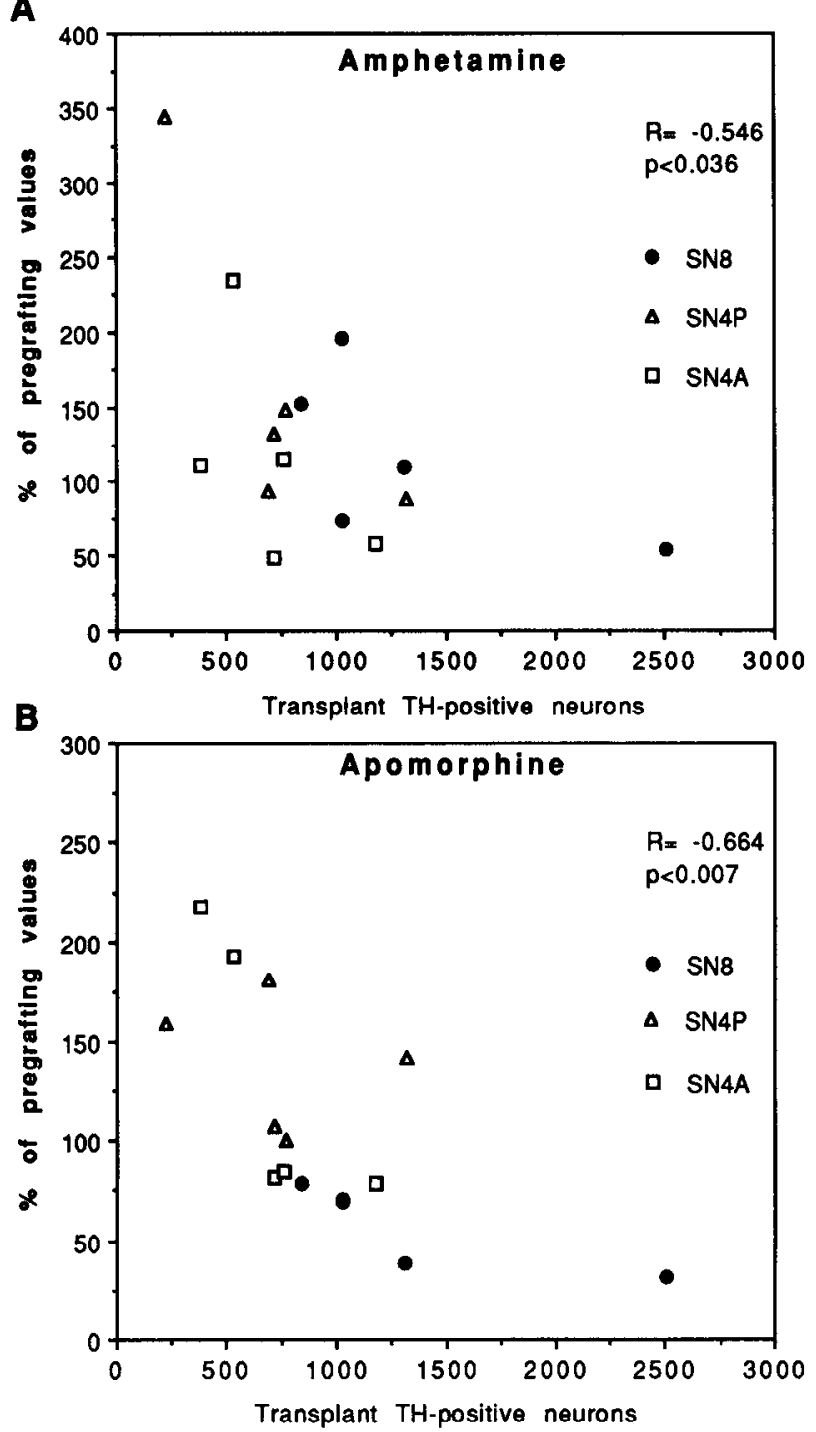

C
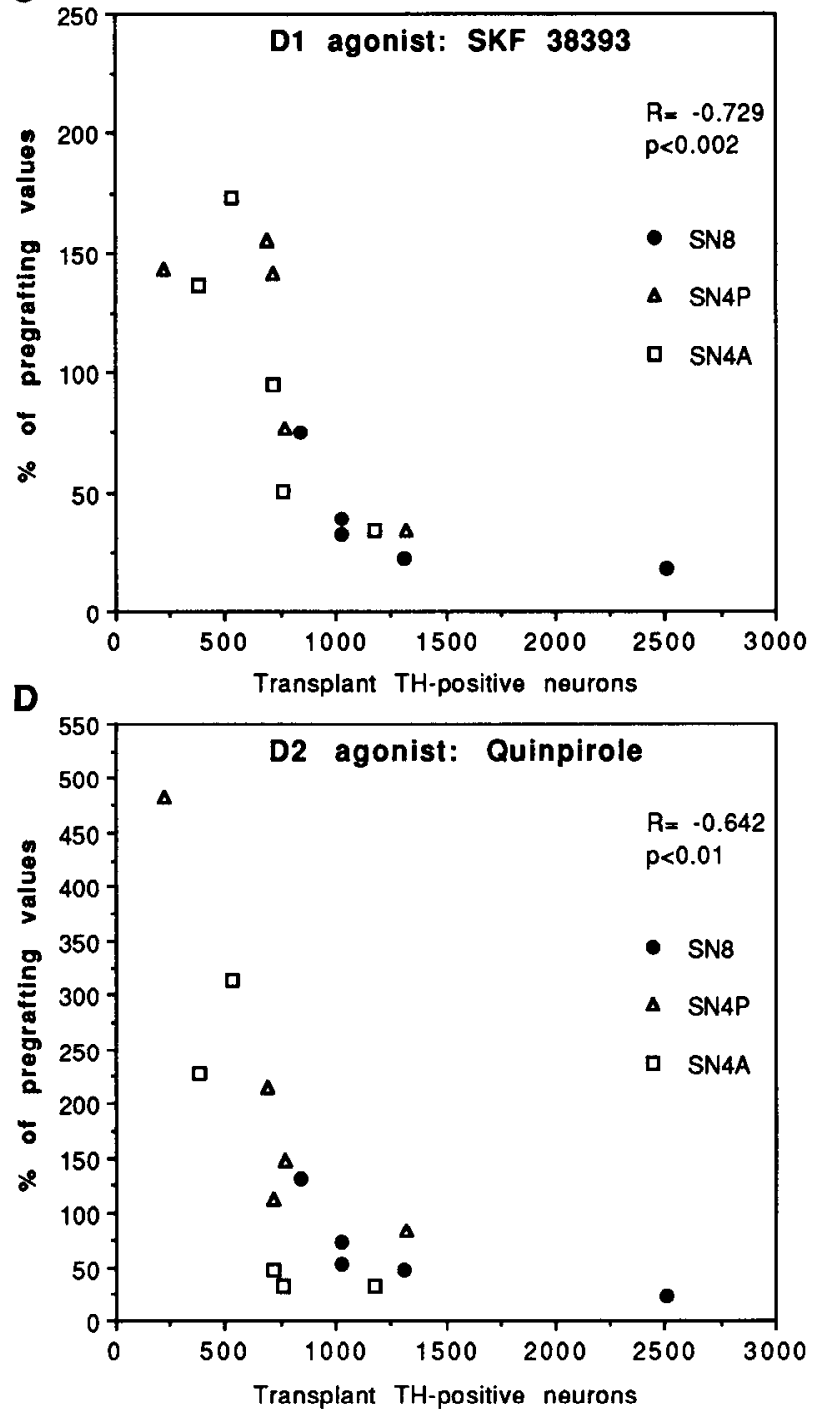

Figure 8. Correlation between the number of TH-positive neurons and the rotation asymmetry expressed as percentage of pregrafting values for the second postgrafting test. There is a significant linear-linear relationship for all dopaminergic agonists $(B-D)$; amphetamine $(A)$ is less clear (simple regression analysis). However, the linear-logarithmic correlations were stronger (see Table 2 ). Only animals with intranigral VM grafts were included in this analysis $(n=15)$.

within the SN. Interestingly, the magnitude of reduction of agonist-induced turning seen with the present intranigral VM grafts is close to, or only slightly less than, that obtaincd with VM grafts implanted into the striatum. This suggests that the intranigral grafts are quite efficient in normalizing dopamine receptor supersensitivity throughout the striatonigral neurons (i.e., not only on the axon terminals but also at the cell body and dendritic level). Other striatal dopamine receptor-bearing neurons, such as the striatopallidal neurons and the cholinergic interneurons, are, however, unlikely to be affected by the intranigral grafts.

The functional significance of dendritically released dopamine in the $\mathrm{SNr}$ in the intact animal has been highlighted in a series of reports (Cheramy et al., 1981; Björklund and Lindvall, 1986; Robertson et al., 1991; Kalivas, 1993). The behavioral response induced by dopaminergic agonists in 6-OHDA-lesioned rats is to a significant degree elicited via nigral mechanisms, and the effects seen after intranigral application of agonists on turning behavior and locomotion are similar to those elicited in the striatum (Kozlowski et al., 1980; Jackson and Kelly, 1983; Robertson and Robertson, 1989; LaHoste and Marshall, 1990; Orosz and Bennett, 1992). Available data suggest that dopamine stimulates $\mathrm{D} 1$ receptors on GABAergic striatonigral terminals in the $\mathrm{SNr}$, thereby causing a GABA-mediated inhibition of the GABAergic output neurons in the SNr. This, in turn, results in a disinhibition of the thalamus, superior colliculus, and pedunculopontine nucleus (Chevalier and Deniau, 1990; Gerfen, 1992; Robertson, 1992). This disinhibitory mechanism is consistent with previous reports showing that the striatonigrotectal pathway plays an important role in the expression of turning behavior in cats (Motles et al., 1988) and rats (Kilpatrick et al., 1982). In 6-OHDA-lesioned rats treatment with a D1 receptor agonist causes an increased GABA release from the striatonigral terminals due to an upregulated D1 receptor response. This, in turn, depresses the activity of the inhibitory $\mathrm{SNr}$ neurons and 
thereby activates the motor nuclei (e.g., superior colliculus), producing a circling response.

The mechanism by which intranigral VM grafts induce functional recovery in the rotation test seems to be related to this gating of striatal outflow of basal ganglia information. In 6-OHDA-lesioned rats, Weick et al. (1990) have shown that systemic administration of SKF 38393, or iontophoresed GABA, causes a $40 \%$ or $70 \%$ reduction of baseline firing ratc, respcctively, of $\mathrm{SNr}$ neurons. These effects could be completely abolished by a $19 \mathrm{~d}$ treatment with an intermittent, but not continuous, L-dopa regimen. It was suggested that pulsatile or phasic activation of dopamine receptors, rather than a continuous unphysiological supply of dopamine, is required to normalize D1and GABA-mediated changes in the activity of the SNr output neurons in 6-OHDA-lesioned rals. The results of Weick et al. (1990) thus provide support for the idea that intranigral graftderived dopamine release may serve this gating control in the $\mathrm{SNr}$ and probably in a more physiological manner than standard drug treatment. The intranigral location could favor also the establishment of a regulatory afferent fiber input to the grafted dopamine neurons, for example, by the excitatory afferents from the cortex and the subthalamic nucleus, which are likely to be important for the induction of pulsatile burst firing in the nigrostriatal dopamine neurons (Grace, 1990). It is conceivable, therefore, that intranigral VM grafts could reinstate a more physiological dopamine release pattern, driven by adequate afferent inputs, than has been shown for the ectopically placed intrastriatal VM grafts.

It is interesting to note that there are clear differences in the pattern of amelioration of drug-induced rotation between intranigral and intrastriatal fetal VM grafts. The main difference is the lack of effect of intranigral grafts on amphetamine-induced turning, while dopamine receptor agonist-induced turning is markedly reduced by both types of transplants. The amphetamine-induced turning response is caused by dopamine release in the striatum, which is greatly reduced on the lesioned side in the unilaterally 6-OHDA-lesioned rats. The restoration of striatal dopamine release seems necessary to counteract this imbalance in the lesioned rat, as indicated by the effect of intrastriatal grafts (Nikkhah et al., 1993). The two principal striatal output structures, the $\mathrm{SNr}$ and the globus pallidus, are both likely to play a role in the mediation of drug-induced turning in unilaterally 6-OHDA-lesioned rats. Previous pharmacological studies have indicated that the D1 receptor-mediated turning response, in particular, is mediated via the nigral output route (Herrera-Marschitz and Ungerstedt, 1984). This is consistent with the present observations that the D1 response was the one that was most consistently influenced by the intranigral grafts.

Another difference between the intranigral and the intrastriatal VM grafts is the close correlation seen between the number of surviving intranigral $\mathrm{TH}$-positive transplant neurons and the degree of functional compensation in the dopamine agonistinduced turning tests. In a previous study on intrastriatal VM grafts, Rioux et al. $(1991 \mathrm{a}, \mathrm{b})$ found no significant correlation between the number of surviving TH-positive, cells and the reduction of the pregrafting circling response to apomorphine, CY-208243 (D1 agonist), or LY 171555 (D2 agonist). There was, however, a significant trend suggesting that groups of rats with higher TH-positive cell numbers also showed a higher degree of compensation or overcompensation in the amphetamine-induced rotation test. In the study of Sauer et al. (1992) there was a direct correlation between these two parameters, such that there was a plateau recovery level for amphetamineinduced rotation ( $100 \%$ or greater compensation) with around 2000 intrastriatal TH-positive graft neurons, and that $50 \%$ reduction was reached with around 600 surviving TH-positive neurons (Sauer et al., 1992). This is about 50\% lower than the number of intranigral TH-positive graft neurons required to achieve functional compensation in the dopamine agonist rotation test (e.g., 1000-1300 TH-positive cells required to obtain $>50 \%$ reduction).

In the present study, the degree of functional compensation was closely correlated with the number of surviving TH-positive neurons, and not to the graft placement (anterior vs posterior) nor the number of injection tracks (four vs eight) within the SN. This finding is interesting in light of the recent anatomical tracing study by Deniau et al. (1992), where the nigrocollicular neurons were found to be localized in the middle part of the $\mathrm{SNr}$, whereas the nigrothalamic neurons originated mainly from the anterior third, and the nigrotegmental neurons from the caudal third. For the intranigral VM micrografts there was an equal chance in each transplant subgroup (SN4A, SN4P, SN8) to cover the middle third of the $\mathrm{SNr}$, but not the anterior or posterior portion. Our results appear to be consistent, therefore, with the earlier proposal that the nigrocollicular pathway is a major route for the expression of turning behavior in 6-OHDAlesioned rats.

The extent to which the intranigral VM grafts can reduce dopamine agonist turning (by $40-65 \%$ ) is remarkable in view of the fact that the caudate-putamen remains denervated in these animals. Dawson et al. (1991) have shown that VM grafts placed in the striatum can downregulate dopamine receptors not only in the reinnervated striatum but also in the ipsilateral $\mathrm{SN}$, suggesting that the effect on these receptors is transmitted anterogradely along the striatonigral pathway. In analogy with these observations it seems possible that the effect on intranigral VM grafts on dopamine receptor expression is transmitted retrogradely to involve the entire striatonigral neuron, and not just their axon terminals in the SNr. It would be of great interest to analyze this further by dopamine receptor binding studies as well as exploring the functional effects of intranigral VM micrografts on other types of behavioral tests, such as complex sensorimotor behavior and skilled forelimb use. Studies along these lines are now in progress.

In summary, the results of the present study demonstrate that fetal dopaminergic micrografts placed into the SN can become morphologically well integrated and induce substantial functional effects in the rat PD model. The results highlight the importance of nigral dopaminergic mechanisms for graft-induced behavioral recovery and suggest new possibilities for the development of more effective transplantation strategies in Parkinson's discase.

The present results raise the possibility that combined grafts involving both the striatum and the SN may induce more substantial functional compensation than grafts placed in the striatum alone. Experiments along these lines may provide new insight into the mechanisms by which the dopaminergic nigrostriatal system influences sensorimotor behavior within the basal ganglia circuitry. Such studies should also help to clarify the functional implications of dopamine released from independent grafts at multiple target sites and the importance of dopaminergic mechanisms in the $\mathrm{SN}$ for graft-induced functional recovery in the rat PD model. 


\section{References}

Abercrombie M (1946) Estimation of nuclear population from microtome sections. Anat Rec 94:239-247.

Abrous DN, Torres EM, Dunnett SB (1993) Dopaminergic grafts implanted into the neonatal or adult striatum: comparative effects on rotation and paw reaching deficits induced by subsequent unilateral nigrostriatal lesions in adulthood. Neuroscience 54:657-668.

Björklund A (1992) Dopaminergic transplants in experimental parkinsonism: cellular mechanisms of graft-induced functional recovery. Curr Opin Neurobiol 2:683-689.

Björklund A, Lindvall O (1986) Catecholaminergic brain stem regulatory systems. In: Handbook of physiology: the nervous system. Intrinsic regulatory systems in the brain (Bloom FE, ed), pp 155-235. Bethesda: American Physiological Society.

Björklund A, Stenevi U, Schmidt RH, Dunnett SB, Gage FH (1983) Intracerebral grafting of neuronal cell suspensions. I. Introduction and general methods of preparation. Acta Physiol Scand 522:1-7.

Cheramy A, Leviel V, Glowinski J (1981) Dendritic release of dopamine in the substantia nigra. Nature 289:537-542.

Chevalier G, Deniau JM (1990) Disinhibition as a basic process in the expression of striatal functions. Trends Neurosci 13:277-280.

Dawson TM, Dawson VL, Gage FH, Fisher LJ, Hunt MA, Wamsley JK (1991) Functional recovery of supersensitive dopamine receptors after intrastriatal grafts of fetal substantia nigra. Exp Neurol 111:282292.

Deniau JM, Chevalier G (1992) The lamellar organization of the rat substantia nigra pars reticulata: distribution of projection neurons. Neuroscience 46:361-377.

Doucet G, Murata Y, Brundin P, Bosler O, Mons N, Geffard M, Ouimet CC, Björklund A (1989) Host afferents into intrastriatal transplants of fetal ventral mesencephalon. Exp Neurol 106:1-19.

Dunnett SB, Björklund A, Schmidt RH, et al. (1983) Intracerebral grafting of neuronal cell suspensions. IV. Behavioural recovery in rats with unilateral 6-OHDA lesions following implantation of nigral cell suspensions in different forebrain sites. Acta Physiol Scand 522:2937.

Dunnett SB, Whishaw IQ, Rogers DC, Jones GH (1987) Dopaminerich grafts ameliorate whole body motor asymmetry and sensory neglect but not independent limb use in rats with 6-hydroxydopamine lesions. Brain Res 415:63-78.

Gerfen CR (1992) The neostriatal mosaic: multiple levels of compartmental organization. Trends Neurosci 15:133-139.

Groenewegen HJ, Wouterlood FG (1990) Light and electron microscopic tracing of neuronal connections with Phaseolus vulgaris-leucoagglutinin (PHAL-L), and combinations with other neuroanatomical techniques. In: Handbook of chemical neuroanatomy, Vol 8, Analysis of neuronal microcircuits and synaptic interactions (Björklund A, Hökfelt T, Wouterlood FG, van den Pol AN, eds), pp 47124. Amsterdam: Elsevier.

Herman JP, Choulli K, Geffard M, Nadaud D, Taghzouti K, LeMoal $M$ (1986) Reinncrvation of the nuclcus accumbens and frontal cortex of the rat by dopaminergic grafts and effects on hoarding behavior. Brain Res 372:210-216.

Herrera-Marschitz M, Ungerstedt U (1984) Evidence that striatal efferents relate to different dopamine receptors. Brain Res 323:269278.

Hökfeit T, Mårtenson R, Björklund A, Kleinau S, Goldstein M (1984) Distributional maps of tyrosine-hydroxylase-immunoreactive neurons in the rat brain. In: Handbook of chemical neuroanatomy, Vol 2. Classical transmitters in the CNS (Björklund A, Hökfelt T, eds), pp 277-379. Amsterdam: Elsevier.

Jackson EA, Kelly PH (1983) Nigral dopaminergic mechanisms in drug-induced circling. Brain Res Bull 11:605-611.

Kalivas PW (1993) Neurotransmitter regulation of dopamine neurons in the ventral tegmental area. Brain Res Rev 18:75-113.

Kilpatrick IC, Collingridge GL, Starr MS (1982) Evidence for the participation of nigrotectal gamma-aminobutyrate-containing neurons in striatal and nigral-derived circling in the rat. Neuroscience $7: 207-222$.
Kozlowski MR, Sawyer S, Marshall JF (1980) Behavioral effects and supersensitivity following nigral dopamine receptor stimulation. $\mathrm{Na}$ ture 287:52-54.

LaHoste GJ, Marshall JF (1990) Nigral D-1 and striatal D-2 receptors mediate the behavioral effects of dopamine agonist. Behav Brain Res 38:233-242.

Motles E, Infante C, Leiva J, Saavedra H, Martinez I (1988) Output pathway for turning behavior from the neostriatum and substantia nigra in cats. Brain Res 473:65-73.

Nikkhah G, Duan W-M, Knappe U, Jödicke A, Björklund A (1993) Restoration of complex sensorimotor behavior and skilled forelimb use by a modified nigral cell suspension transplantation approach in the rat Parkinson model. Neuroscience 56:33-43.

Nikkhah G, Cunningham MG, Jödicke A, Knappe U, Björklund A (1994) Improved graft survival and striatal reinnervation using a microtransplantation approach in the rat parkinson model. Brain Res 633:133-143.

Orosz D, Bennett JP (1992) Simultaneous microdialysis in striatum and substantia nigra suggests that the nigra is a major site of action of L-dihydroxyphenylalanine in the "hemiparkinsonian" rat. Exp Neurol 115:388-393.

Richfield EK, Penney JB, Young AB (1989) Anatomical and affinity state comparisons between dopamine D- 1 and D-2 receptors in the rat central nervous system. Neuroscience 30:767-777.

Rioux L, Gaudin DP, Bui LK, Gregoire L, DiPaolo T, Bedard PJ (1991a) Correlation of functional recovery after a 6-hydroxydopamine lesion with survival of grafted fetal neurons and release of dopamine in the striatum of the rat. Neuroscience 40:123-131.

Rioux L, Gaudin DP, Cagnon C, Di PT, Bedard PJ (1991b) Decrease of behavioral and biochemical denervation supersensitivity of rat striatum by nigral transplants. Neuroscience 44:75-83.

Robertson GS, Robertson HA (1989) Evidence that L-dopa-induced rotational behavior is dependent on both striatal and nigral mechanisms. J Neurosci 9:3326-3331.

Robertson GS, Damsma G, Fibiger HC (1991a) Characterization of dopamine release in the substantia nigra by in vivo microdialysis in freely moving rats. J Neurosci 11:2209-2216.

Robertson GS, Fine A, Robertson HA (1991b) Dopaminergic grafts in the striatum reduce $D-1$ but not D-2 receptor-mediated rotation in 6-OHDA-lesioned rats. Brain Res 539:304-311.

Robertson HA (1992) Dopamine receptor interactions: some implications for the treatment of Parkinson's disease. Trends Neurosci 15: 201-206.

Sauer H, Frodl EM, Kupsch A, ten Bruggencate G, Oertel WH (1992) Cryopreservation, survival and function of intrastriatal fetal mesencephalic grafts in a rat model of Parkinson's discasc. Exp Brain Res 90:54-62.

Schmidt RH, Björklund A, Stenevi U, Dunnett SB, Gage FH (1983) Intracerebral grafting of neuronal cell suspensions. III. Activity of intrastriatal nigral suspension implants as assessed by measurements of dopamine synthesis and metabolism. Acta Physiol Scand 522:19 28.

Ungerstedt $U$, Arbuthnott $G$ (1970) Quantitative recording of rotational behavior in rats after 6-hydroxy-dopamine lesions of the nigrostriatal dopamine system. Brain Res 24:485-493.

von Krosigk M, Smith Y, Bolam JP, Smith AD (1992) Synaptic organisation of gabaergic inputs from the striatum and the globus pallidus onto neurons in the substantia nigra and retrorubral field which project to the medullary reticular formation. Neuroscience 50:531549.

Weick BG, Engber TM, Susel Z, Chase TN, Walters JR (1990) Responses of substantia nigra pars reticulata neurons to GABA and SKF 38393 in 6-hydroxydopamine-lesioned rats are differentially affected by continuous and intermittent levodopa administration. Brain Res $523: 16-22$

Wictorin K, Ouimet CC, Björklund A (1989) Intrinsic organization and connectivity of intrastriatal striatal transplants in rats as revealed by DARPP-32 immunohistochemistry: specificity of connections with the lesioned host brain. Eur J Neurosci 1:690-701. 